\title{
The effect of smoking on physiological decongestion of the nasal mucosa in human*
}

\author{
H. Thorold ${ }^{1}$, M. Bende ${ }^{2}$ \\ 1 Linköping University, Linköping, Sweden \\ 2 Department of Otorhinolaryngology, Central Hospital, Skövde, Sweden
}

\begin{abstract}
SUMMARY
Background: Exercise is known to decongest the nasal mucosa resulting in increased nasal patency. In a recent study, it was suggested that smoking might influence the effect of exercise on the nasal mucosa. This implies that smoking may damage the normal nasal physiology, which has not previously been shown. The aim of this study was to investigate whether there was a difference in nasal mucosal reaction to exercise between smokers and non-smokers.

Methodology: Forty-two smokers and non-smokers underwent acoustic rhinometry to register nasal geometry before and after cycling on an ergometer cycle. A structured interview was used for questions about smoking habits and airway symptoms.

Results: Both smokers and non-smokers had a significant increase in MCA (minimal crosssection area) and total nasal volume after exercise. There was no statistical significant difference between smokers and non-smokers.

Conclusions: Smoking does not seem to affect the normal physiological decongestion of the nasal mucosa after exercise.
\end{abstract}

Key words: acoustic rhinometry, smoking, exercise, normal physiology, decongestion

\section{INTRODUCTION}

Most humans have a preference for nasal breathing over oral breathing at rest. Oral or oro-nasal breathing is more often used during increased ventilation, speech, and nasal obstruction. At exercise, when there is need for increased ventilation, nasal breathing is a major component ${ }^{(1)}$. It is well known that during exercise there is decongestion of the nasal mucosa that results in increased nasal patency and it has been suggested that maximal intense exercise gives maximal decongestion ${ }^{(2)}$. The physiological benefit seems to be increased airflow to the lung, which leads to increased oxygenation ${ }^{(1,3)}$. This mechanism is likely regulated by the sympathetic nervous system ${ }^{(4)}$.

In a recent thesis, a coincidental finding suggested that smoking might influence nasal patency during exercise. In that prospective cohort study, Irander et al. investigated the nasal mucosa in 67 subjects with and without family history of allergy, looking for objective markers of allergy development. Subjects underwent acoustic rhinometry, the results of which were analyzed in relation to allergic manifestation. It was found that the total nasal volume remained unchanged after exercise in smokers, while it increased significantly in nonsmokers $(\mathrm{p}<0.0001)^{(5)}$. Thus, the nasal mucosa was shown to decongest after exercise in non-smokers, but it was not affected in smokers.
In prior studies on the decongestion of the nasal mucosa after exercise, the difference between smokers and non-smokers has not been investigated. If smokers respond differently from non-smokers, this implies that smoking may cause neurological damage to the normal nasal physiology, which has not previously been shown. The aim of this study is to investigate whether there is a difference in the nasal mucosa reaction to exercise between smokers and non-smokers.

\section{SUBJECTS AND METHOD}

Subjects

Forty-two healthy individuals were recruited through newspaper advertising, 21 smokers and 21 non-smoking controls. The groups were age- and sex-matched with 11 women and 10 men, aged between 22 and 73 years old in each group. The mean age in smokers was 46.3 years $(95 \%$ confidence interval 38.8-53.9 years) and 45.5 years (95\% confidence interval 38.4 52.5 years) in the non-smoking group. The subjects in the smoking group smoked daily and had a smoking history of more than one year. Five non-smokers had a history of smoking (4 to 15 pack-years, i.e. the number of packages of cigarettes smoked per day, 20 cigarettes per package, multiplied by numbers of years of smoking), but had not smoked for the last three years. Criteria for inclusion were age over 18 years and the ability to cycle on an ergometer cycle. Exclusion criteria 
were present signs of nasal disease. Information and instructions were given both orally and in writing. Signed informed consent was obtained from each participant. The study was carried out in accordance with the Declaration of Helsinki and was approved by the Ethics Committee at the University of Gothenburg (090-09).

\section{Questionnaire}

A standardized and validated questionnaire previously used in large epidemiological studies was used to perform a structured interview about smoking habits and airway symptoms ${ }^{(6)}$. The airway symptoms were identified using 5 questions:
1. Are you bothered by nasal secretions?
2. Are you bothered by nasal blockage?
3. Do you have coughing problems?

If the answer to any of these questions was yes, the subject was asked whether the symptoms occurred daily, frequently, or occasionally.

The subject was also asked:
4. Do you ever have problems with breathing?
5. Do you find it harder to breath when it is cold?

\section{Acoustic rhinometry}

Heart rate was measured using a pulse watch (Polar T31 transmitter, China) and nasal patency with acoustic rhinometry (Rhin 2000, SR Electronics AS, Lynge, Denmark) ${ }^{(7)}$. This technique allows the measurement of minimal cross-section area (MCA) and total nasal volume before and after exercise ${ }^{(8)}$. Even though acoustic rhinometry is a preferred method of measuring nasal patency, it can be difficult to make a proper recording. It is important to ensure that there is no leakage between the nosepiece and the nose. If the nosepiece deforms the nostril, that can also give rise to erroneous results. A pilot study with extensive training in use of the equipment was performed prior to this study, to ensure reproducibility of the results.

Size-adjusted nosepieces were chosen for each individual and different nosepieces were used for the right and left nostrils. Rhin 2000 measures the volume 22-54 mm from the nasal aperture, since this parameter is regarded as best to reflect mucosal changes in nasal patency ${ }^{(9)}$. MCA was calculated from the second notch on the area-distance curve, which represents the area between the anterior portion of the inferior turbinate and the septum in the nasal valve area, by using the computerized program in Rhin 2000. To avoid any effect of the nasal cycle, the mean of the right and the left side was used in the calculations. All measurements were taken and recorded with the same equipment and by the same researcher.

The first measurements were taken with the subject at rest after 15 minutes acclimatization to indoor temperature and humidity. The second were taken after the subject had been cycling on an ergometer cycle and had either reached a heart rate of $150-160$ beats per minute (bpm) or was unable to continue.
Table 1. Minimal cross-section area (MCA) and mean volume in smokers and non-smokers before and after exercise, (mean \pm SEM).

\begin{tabular}{lcccc}
\hline & \multicolumn{2}{c}{ MCA $\left[\mathrm{cm}^{2}\right]$} & \multicolumn{2}{c}{ Mean volume $\left[\mathrm{cm}^{3}\right]$} \\
\hline Smokers & Before & After & Before & After \\
Non-smokers & $0.70 \pm 0.05$ & $0.94 \pm 0.06$ & $6.0 \pm 0.32$ & $8.9 \pm 0.54$ \\
\hline
\end{tabular}

Table 2. Mean increase in MCA and volume in smokers and nonsmokers before and after exercise, (mean \pm SEM).

\begin{tabular}{lcc}
\hline & $\begin{array}{c}\text { Mean increase in } \\
\text { MCA }\left[\mathrm{cm}^{2}\right]\end{array}$ & $\begin{array}{c}\text { Mean increase in } \\
\text { mean volume }\left[\mathrm{cm}^{3}\right]\end{array}$ \\
\hline Smokers & $0.24 \pm 0.05$ & $2.92 \pm 0.40$ \\
Non-smokers & $0.18 \pm 0.05$ & $2.32 \pm 0.40$ \\
\hline
\end{tabular}

\section{Statistical analysis}

Independent samples $t$-test $(\mathrm{H} 0=$ no difference between smokers and non-smokers) and chi-square were calculated using JMP 7.0 (SAS Institute Inc., NC, USA) for statistical analysis.

\section{RESULTS}

The smokers started at a mean heart rate of $78 \mathrm{bpm}$ (95\% confidence interval $[\mathrm{CI}]=72-84 \mathrm{bpm}$ ), while the non-smokers started at a mean of $70 \mathrm{bpm}(95 \% \mathrm{CI}=65-76 \mathrm{bpm})$. After exercise, smokers reached $146 \mathrm{bpm}(95 \% \mathrm{CI}=140-151 \mathrm{bpm})$ and non-smokers, $146 \mathrm{bpm}$ (95\% CI = 141-152 bpm). The total nasal volume was significantly larger in smokers than in nonsmokers before exercise, but the MCA did not differ between the groups.

After exercise, mean volume and MCA increased significantly in both groups (Tables 1 and 2). There was no statistically significant difference in the increase of either MCA or volume between smokers and non-smokers. The extent of the decongestive effect was independent of the number of cigarettes smoked.

Of the smokers, 2 were bothered by nasal secretions, 1 daily and 1 occasionally. In contrast, 6 of the non-smokers experienced secretions: 3 daily, 1 frequently, and 2 occasionally. There was a significant difference in how often smokers and non-smokers were bothered by nasal secretions.

Nasal blockage bothered 3 smokers and 3 non-smokers: 1 in each group daily and 2 in each group occasionally. Coughing problems were reported by 6 smokers, 3 daily and 3 occasionally. In contrast, 2 non-smokers reported coughing problems, 1 frequently and 1 occasionally.

Problems with breathing were reported by 2 smokers and 1 non-smoker, and 3 smokers and 1 non-smoker answered "yes" when asked if they find it harder to breathe when it is cold (Table 3).

\section{DISCUSSION}

Even though acoustic rhinometry is a preferred method of measuring nasal patency, it can be difficult to make a proper record- 
Table 3. Prevalence of upper and lower airway symptom in both smokers and non-smokers.

\begin{tabular}{llccc}
\hline $\begin{array}{l}\text { Are you bothered } \\
\text { by nasal secretions? }\end{array}$ & Yes & Daily & Frequently Occasionally \\
$\quad$ Smokers & & & & \\
$\quad$ Non-smokers & $\mathbf{6}$ & 1 & - & 1 \\
$\begin{array}{l}\text { Are you bothered } \\
\text { by nasal blockage? }\end{array}$ & $\mathbf{6}$ & 3 & 1 & 2 \\
$\quad \begin{array}{l}\text { Smokers } \\
\quad \text { Non-smokers }\end{array}$ & $\mathbf{3}$ & 1 & - & 2 \\
$\begin{array}{l}\text { Do you have } \\
\text { coughing problems? }\end{array}$ & $\mathbf{3}$ & 1 & - & 2 \\
$\quad \begin{array}{l}\text { Smokers } \\
\quad \text { Non-smokers }\end{array}$ & $\mathbf{6}$ & 3 & - & 3 \\
$\begin{array}{l}\text { Do you ever have } \\
\text { problems with breathing? }\end{array}$ & 2 & - & 1 & 1 \\
$\quad \begin{array}{l}\text { Smokers } \\
\text { Non-smokers }\end{array}$ & $\mathbf{2}$ & & \\
$\begin{array}{l}\text { Do you find it harder } \\
\text { breathing when it is cold? }\end{array}$ & $\mathbf{1}$ & & \\
$\begin{array}{l}\text { Smokers } \\
\text { Non-smokers }\end{array}$ & $\mathbf{3}$ & & \\
\hline
\end{tabular}

ing. It is important to ensure that there is no leakage between the nosepiece and the nose. If the nosepiece deforms the nostril, that can also give rise to erroneous results. To ensure reproducibility of the results, a pilot study with extensive training in use of the equipment was performed prior to this study.

From this study and others, it is unclear how smoking affects human nasal patency at rest. One study shows that smokers have a smaller MCA and nasal volume than non-smokers, while another implies the opposite ${ }^{(10,11)}$ A third shows no significant difference in mean nasal volume and MCA between smokers and non-smokers ${ }^{(12)}$.

This study could not verify the findings in Irander's thesis that smokers responded differently from non-smokers regarding the decongestive effect of exercise. Since the smokers in our study had been smoking from 1 to 35 pack-years and smoked between 4 and 20 cigarettes per day, they arguably represent the smoking public in general. Whereas the smokers in our study had been smoking daily for many years, the subjects in the study by Irander did not smoke regularly, nor had they been smoking for long (personal communication). This needs to be considered when comparing our results with theirs. Most of our non-smokers had never smoked, and the five who were ex-smokers had quit smoking several years ago. Although it would have been preferable that none of the non-smokers had a smoking history, it is unlikely that would have had a significant impact on the results.

The smokers started with a higher heart rate than the nonsmokers. This may have been caused by anxiety about the exercise or about being smokers in a healthcare institution.
The stress of knowing that their results would be compared with non-smokers could have affected the results as well. The heart rate of subjects before exercise could be a possible explanation for the lack of decongestion in the smokers in the study by Irander. If the subject has a high heart rate from the beginning, the sympathetic nervous system may already be activated and the nasal mucosa already decongested.

In conclusion, smoking does not seem to affect the normal physiological decongestion of the nasal mucosa after exercise.

\section{ACKNOWLEDGEMENTS}

The authors are grateful to Christel Larsson for introducing the technique of acoustic rhinometry.

\section{REFERENCES}

1. Cole P. Upper respiratory airflow. In: Proctor DF, Andersen I, eds. The nose - upper airway physiology and the atmospheric environment. Amsterdam: Elsevier Biomedical Press, 1982; 163-189.

2. Broms P. Rhinomanometry. Procedures and criteria for distinction between skeletal stenosis and mucosal swellning. Acta Otolaryngol 1982; 94: 361-370.

3. Eccles R. Neurological and pharmacological considerations. In: Proctor DF, Andersen I, eds. The nose - upper airway physiology and the atmospheric environment. Amsterdam: Elsevier Biomedical Press, 1982; 202-214.

4. Olsson P, Bende M. Sympathetic neurgenic control of blood flow in human nasal mucosa. Acta Otolaryngol 1986; 102: 482-487.

5. Irander K. An 18 year follow-up of allergy development - findings of nasal markers of allergic inflammation. Linköping Studies in Health Sciences, Thesis No. 89: 2008.

6. Åkerlund A, Millqvist E, Oberg D, et al. Prevalence of upper and lower airway symptoms: the Skövde population-based study. Acta Otolaryngol 2006; 126: 483-488.

7. Hilberg O, Jackson AC, Swift DL, et al. Acoustic rhinometry: Evaluation of nasal cavity geometry by acoustic reflection. J Appl Physiol 1989; 66: 295-303.

8. Clement PA, Gordts F; Standardisation Committee on Objective Assessment of the Nasal Airway, IRS, and ERS. Consensus report on acoustic rhinometry and rhinomanometry. Rhinology 2005; 43: 169-179.

9. Straszek S, Schlünssen V, Sigsgaard T, Pedersen OF. Reference values for acoustic rhinometry in decongested school children and adults: the most sensitive measurement for change in nasal patency. Rhinology 2007; 45: 36-39.

10. Zavras AI, al-Bultan T, Jackson A, et al. Exposure to passive smoking and other predictors of reduced nasal volume in children 7 to 12 years old. J Clin Pediatr Dent 1997 Summer; 21: 295-303.

11. Maeda Y, Okita W, Ichimura K. Increased nasal patency caused by smoking and contraction of isolated human nasal mucosa. Rhinology 2004; 42: 63-67.

12. Mohebbib A, Farhadi M, Erfan A. Assessment of nasal volume and cross-sectional area by acoustic rhinometry in a sample of normal adult iranians. Arch Iran Med 2008; 11: 555-558.

Professor Mats Bende, MD, PhD

ENT Department

Central Hospital

SE54185 Skövde

Sweden

E-mail: mats.bende@vgregion.se 